Research Article

\title{
Theoretical Analysis and Experimental Research into the Mechanical Properties of Al-Ti-Al Symmetrical Laminated Plate
}

\author{
Xia Yang, ${ }^{1}$ Yingchao Ma, ${ }^{1,2}$ Dongsheng He, ${ }^{1}$ Xiaozhong Du $\mathbb{D}^{1},{ }^{1}$ and Rongjun Wang ${ }^{1}$ \\ ${ }^{1}$ College of Mechanical Engineering, Taiyuan University of Science and Technology, Taiyuan 030024, China \\ ${ }^{2}$ Shanxi Jianghuai Heavy Industry Co., Ltd., Jincheng 048026, China \\ Correspondence should be addressed to Xiaozhong Du; duxz@tyust.edu.cn
}

Received 18 September 2019; Revised 9 January 2020; Accepted 21 February 2020; Published 30 March 2020

Academic Editor: Pietro Russo

Copyright (c) 2020 Xia Yang et al. This is an open access article distributed under the Creative Commons Attribution License, which permits unrestricted use, distribution, and reproduction in any medium, provided the original work is properly cited.

In order to have both the surface corrosion resistance of aluminum alloy and the high specific strength characteristics of titanium alloy, titanium alloy TC4, and aluminum alloy 6061 can be used to make aluminum-titanium-aluminum (Al-Ti-Al) three-layer laminated plate by hot rolling. In this paper, the classical laminated plate theory was used to calculate the stiffness, specific stiffness, strength, and specific strength of the laminated plate. The results showed that when the coating rate of titanium alloy TC4 was 0.5 , bending specific stiffness and bending specific strength were the minimum, but all other parameters increased with the increase of the coating rate of titanium alloy TC4. Therefore, in actual production, the coating rate of titanium alloy should be avoided being 0.5. Then, the rolling experiments of the Al-Ti-Al laminated plate were carried out with different temperatures, reduction rates, and thickness ratios. Finally, the tensile test and energy spectrum analysis of the laminated plate were carried out. The results showed that, with the increase of rolling temperature, the tensile strength, the extensibility, and the thickness of the diffusion layer increased; if the coating rate of titanium alloy TC4 was between 0.2 and 0.33 , the mechanical properties, the bonding strength, and the thickness of the diffusion layer increased with the increase of the coating rate of titanium alloy TC4.

\section{Introduction}

Titanium and titanium alloys have the advantages of low density, high strength, good corrosion resistance, good hightemperature performance, and good biocompatibility, which are widely used in the fields of aerospace, marine vessels, petrochemical industry, and medical devices [1-3]. However, that price of titanium and titanium alloy is relatively valuable, and it is necessary to reduce the use cost of the titanium as a universal type of metal. Aluminum and aluminum alloys have the advantages of low density, low cost, high specific strength, strong corrosion resistance, and good thermal conductivity, which are widely used only after the steel. Aluminum and aluminum alloys have a very important position in architectural decoration, transportation, and sanitary equipment [4-6].

The layer metal laminated materials were made of two or more single-layer metals by suitable composite technology [7-9]. It combined the advantages of single-component metal, which not only made the application value of single metal fully play but also can reduce the amount of precious metal, improve the deficiency of single metal, and better adapt to the industrialization and market-oriented development [10-12]. Titanium and aluminum alloys can be made into layered Ti-Al laminated plates by laminated technology. These laminated plates not only had the titanium alloy's advantages of high-temperature resistance, corrosion resistance, and high specific strength but also had the aluminum alloy's characteristics of low price, good conductivity, and thermal conductivity. It was a kind of layered composite with excellent comprehensive properties, which had good comprehensive application value and development prospect [13-15].

For a long time, national and international experts have done a lot of research on Ti-Al composite technology. Chen et al. [16] prepared a pure Al-pure Ti-pure Al three-layer laminated plate by hot rolling. The microstructure and mechanical properties of the laminated plate were studied. Xia et al. [17] 
obtained TA2 Ti-2A12 Al alloy laminated plate by an explosive composite method and studied its mechanical properties. Wang et al. [18] obtained a Ti-Al laminated plate with the thickness being $6.5 \mathrm{~mm}$ by oxygen-free continuous cast rolling. Luo and Acoff [19] obtained multilayer laminated plates of the pure $\mathrm{Ti}$ and Al by cold rolling. They found that after holding for a certain period of time at a certain temperature, TiAl3 mesophase was produced on one side of the aluminum plate at the interface between titanium and aluminum laminated plates. Guo et al. [20] made a Ti-Al bimetallic tube by explosive welding. It was found that the bonding interface was composed of a straight line and two forms between the straight line and a wavy state. Bataev et al. [21] obtained a multilayer Ti-Al laminated plate by explosive welding and through the subsequent heat treatment found that the intermetallic compound $\mathrm{Al}_{3} \mathrm{Ti}$ was formed when annealed at $630^{\circ} \mathrm{C}$. Ma et al. [22] obtained a Ti-Al composite plate with the thickness being $1.5 \mathrm{~mm}$ by explosion rolling process and optimized the explosive welding process parameters of TA1 and $2 \mathrm{Al}_{2}$. Ma et al. [23] fabricated Ti-6Al-4V/Al 3003/Ti$6 \mathrm{Al}-4 \mathrm{~V}$ laminated composites by hot-roll bonding and investigated the microstructure and mechanical properties of the TiAl-Ti laminated composites. Ma et al. [24] fabricated Al 6061/ Ti-6Al-4V/Al 6061 laminated composites by hot-roll bonding and investigated the effect of rolling temperature and reduction on the microstructure and mechanical properties of $\mathrm{Al}-\mathrm{Ti}-\mathrm{Al}$ laminated composites. Yu et al. [25] investigated the annealing effect on microstructure evolution and deformation mechanism during tensile testing of Al-Ti-Al laminate sheets. Mi et al. [26] fabricated TA2/5052Al/AZ31/5052Al/TA2 five-ply laminates by hot rolling and studied the effect of anisotropy on their microstructures and mechanical properties. Fronczek et al. [27] manufactured $\mathrm{Al}-\mathrm{Ti}$ clads by explosive welding and examined the microstructure evolution of the Al-Ti interface at $825 \mathrm{~K}$ and various annealing time. Jafari and Eghbali [28] produced Ti$\mathrm{Al}-\mathrm{Nb}$ composites by solid-state diffusion bonding through hot pressing and rolling followed by annealing at $700^{\circ} \mathrm{C}$ for 0.5 hours, 1 hour, 1.5 hours, and 2 hours and investigated the morphologies of $\mathrm{TiAl}_{3}$ intermetallic by Scanning Electron Microscopy combined with Energy-dispersive X-ray spectroscopy.

In this paper, the stiffness and strength of the Al-Ti-Al laminated plate were studied by classical laminated plate theory; the effect of the coating rate of titanium alloy on the properties of the laminated plate was obtained. According to the guidance of theoretical calculation results, Al-Ti-Al laminated plate hot rolling experiments were carried out under different temperatures, pressure reduction rates, and coating rates of the titanium plate; and the mechanical properties test and energy spectrum analysis of the rolled laminated plates were carried out. The research work is is of great scientific and practical significance to improve the production technology level of $\mathrm{Ti}-\mathrm{Al}$ laminated plate and promote the application field of laminated materials.

\section{Theoretical Calculation of Mechanical Properties of the Al-Ti-Al Laminated Plate}

The stiffness and strength analysis of laminated plates must be more complicated than the single plates; generally, the single-layer plate of laminated plates is regarded as thin plates with uniform properties. The classical laminated plate theory hypothesis is as follows:

(1) The solid combination is achieved between each layer of the laminated plate, the deformation of each layer is continuous, and the slippage between the layers is ignored, and so, the laminated plate can be regarded as one object.

(2) Ignore the strain in the width direction and make the metal laminated plate in the plane strain state.

(3) The bending deformation of the laminated plate belongs to the range of small deformation [29].

(4) $\sigma_{x}, \sigma_{y}$, and $\tau_{x y}$ represent the normal stress and shear stress of single-layer plate under the action of external force, respectively, and $\varepsilon_{x}, \varepsilon_{y}$, and $\gamma_{x y}$ represent corresponding strain, respectively.

Suppose that the total thickness of the laminated plate is $h$, the layer number of the laminated plate is $n$, and the thickness of the $k$-layer is $Z_{k}-Z_{k-1}$; the structure of the laminated plate is shown in Figure 1 [30].

According to the classical laminated plate theory, in plane strain state, the stress-strain relationship of the single plate is shown as follows:

$$
\left\{\begin{array}{c}
\sigma_{x} \\
\sigma_{y} \\
\tau_{x y}
\end{array}\right\}=\left[\begin{array}{ccc}
Q_{11} & Q_{12} & 0 \\
Q_{21} & Q_{22} & 0 \\
0 & 0 & Q_{66}
\end{array}\right]\left\{\begin{array}{c}
\varepsilon_{x} \\
\varepsilon_{y} \\
\gamma_{x y}
\end{array}\right\}=\left[\begin{array}{ccc}
\frac{E_{1}}{1-v_{1} v_{2}} & \frac{v_{2} E_{1}}{1-v_{1} v_{2}} & 0 \\
\frac{v_{1} E_{2}}{1-v_{1} v_{2}} & \frac{E_{2}}{1-v_{1} v_{2}} & 0 \\
0 & 0 & G_{12}
\end{array}\right]\left\{\begin{array}{c}
\varepsilon_{x} \\
\varepsilon_{y} \\
\gamma_{x y}
\end{array}\right\},
$$

where $E$ is the elastic modulus of the material, $v$ is Poisson's ratio, $Q_{i j}$ is the stiffness matrix coefficient of the single-layer plate, and $G$ is the shear modulus.
2.1. Stiffness Calculation of the Laminated Plate. In this paper, $\mathrm{Al}-\mathrm{Ti}$-Al laminated plate is a symmetrical laminated plate. The base material is titanium alloy TC4, and composite material is 


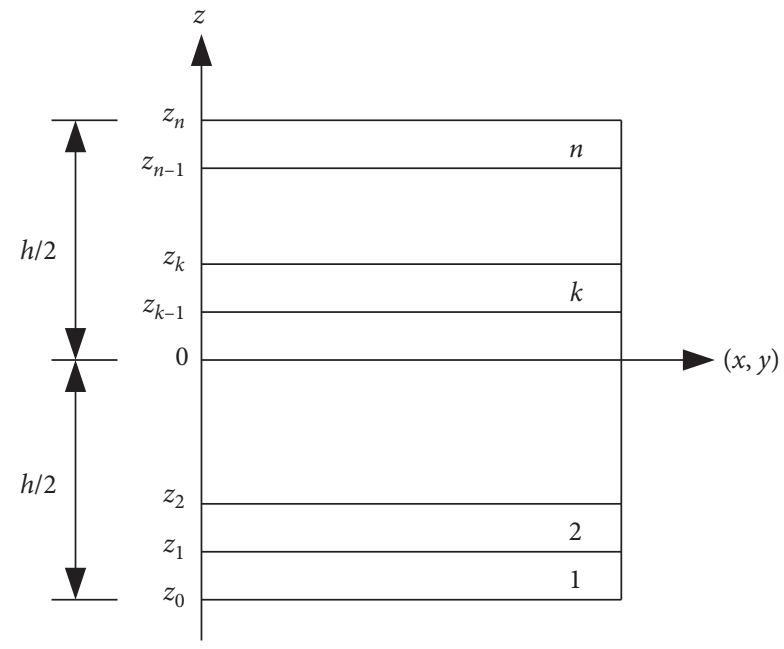

Figure 1: Structure of the $n$-layer laminated plate.

TABLE 1: Material performance parameters.

\begin{tabular}{lcccccc}
\hline Metal & $\rho\left(\mathrm{g} / \mathrm{cm}^{3}\right)$ & $E(\mathrm{MPa})$ & $v$ & $R_{\rho 0.2}(\mathrm{MPa})$ & $R_{m}(\mathrm{MPa})$ & $A(\%)$ \\
\hline 6061 & 2.71 & 68950 & 0.3 & 276 & 310 & 12 \\
TC4 & 4.51 & 117200 & 0.31 & 1100 & 1306 & 8.07 \\
\hline
\end{tabular}

aluminum alloy 6061, which are isotropic materials. Material performance parameters can be seen in Table 1 .

The stiffness coefficient of the laminated plate is as follows [30]:

$$
\left\{\begin{array}{l}
A_{i j}=\sum_{k=1}^{n} Q_{i j}^{(k)}\left(z_{k}-z_{k-1}\right), \\
B_{i j}=\frac{1}{2} \sum_{k=1}^{n} Q_{i j}^{(k)}\left(z_{k}^{2}-z_{k-1}^{2}\right), \\
D_{i j}=\frac{1}{3} \sum_{k=1}^{n} Q_{i j}^{(k)}\left(z_{k}^{3}-z_{k-1}^{3}\right),
\end{array}\right.
$$

where $A_{i j}$ is a stiffness coefficient related to internal force and strain of symmetry plane of the middle-layer metal, which is collectively called tensile stiffness; $D_{i j}$ is the stiffness coefficient related to torsional curvature of internal torque, which is collectively called bending stiffness; and $B_{i j}$ represents the coupling relationship between bending and tension, which is collectively called coupling stiffness [29]. This study is based on the plane strain hypothesis, so the coupling stiffness is 0 . In order to facilitate the comparison of the above stiffness coefficients, these stiffness coefficients and other mechanical parameters are regularized.

Suppose that $N^{*}=N / h, M^{*}=6 M / h^{2}, A_{i j}^{*}=A_{i j} / h$, $B_{i j}^{*}=2 B_{i j} / h^{2}, D_{i j}^{*}=12 D_{i j} / h^{3}, \kappa^{*}=h \kappa / 2$, and the thickness of the whole laminated plate is 1 , the thickness of base material titanium alloy TC4 is $t(0 \leq t \leq 1)$, and the thickness of composite material aluminum alloy 6061 is $(1-t) / 2(0 \leq t \leq 1)$. The expression of the regularization stiffness coefficient of the laminated plate can be obtained, as shown in the following formula:

$$
\left\{\begin{array}{l}
A_{i j}^{*}=t \times\left(Q_{i j}^{(2)}-Q_{i j}^{(1)}\right)+Q_{i j}^{(1)}, \\
B_{i j}^{*}=0, \\
D_{i j}^{*}=t^{3} \times\left(Q_{i j}^{(2)}-Q_{i j}^{(1)}\right)+Q_{i j}^{(1)}, \\
(i, j=1,2,6) .
\end{array}\right.
$$

Assume that titanium alloy TC4 and aluminum alloy 6061 are isotropic materials, so the longitudinal and transverse elastic models are equal, and also the longitudinal and transverse Poisson's ratio. The regularization tensile stiffness coefficient and bending stiffness coefficient are obtained by replacing the performance parameters of TC4 and 6061 into formula (3). $A_{11}^{*}$ represents the tensile stiffness of the laminated plate; $D_{11}^{*}$ represents the bending stiffness of the laminated plate.

$$
\begin{aligned}
A^{*} & =\left[\begin{array}{ccc}
53891 t+75769 & 17464 t+22731 & 0 \\
17464 t+22731 & 53891 t+75769 & 0 \\
0 & 0 & 18214 t+26519
\end{array}\right], \\
D^{*} & =\left[\begin{array}{ccc}
53891 t^{3}+75769 & 17464 t^{3}+22731 & 0 \\
17464 t^{3}+22731 & 53891 t^{3}+75769 & 0 \\
0 & 0 & 18214 t^{3}+26519
\end{array}\right],
\end{aligned}
$$

where $s=t^{3}+3 t$.

The specific stiffness is obtained by the regularization stiffness coefficient divided by the density of the metal plate. The formula for calculating the density of the laminated plate is as follows:

$$
\rho=t\left(\rho_{2}-\rho_{1}\right)+\rho_{1},
$$

where $\rho_{1}$ and $\rho_{2}$ represent the densities of TC4 and 6061 .

The curves of stiffness and specific stiffness of laminated plate 6061-TC4-6061 with the coating rate of titanium alloy can be obtained, as shown in Figure 2.

In Figure 2(a), when the abscissa is 0 , the parameters are those of 6061 ; when the abscissa is 1 , the parameters are those of TC4. With the increase of the thickness of TC4, the tensile stiffness and bending stiffness of the whole laminated plate increase. In Figure 2(b), with the increase of the thickness of TC4, the tensile specific stiffness of the laminated plate increases slowly, and the bending specific stiffness decreases first and then increases. It indicates that the titanium alloy can significantly change the tensile specific stiffness of the laminated plate. When the coating rate of titanium alloy TC4 is about 0.5 , the bending specific stiffness of the laminated plate is the minimum.

2.2. Strength Calculation of the Laminated Plate. The failure process of the laminated plate can be regarded as that under the continuous action of external force; the one layer plate with the weakest performance in the laminated plate fails first, which will change the stress state of the whole laminated plate. The first failure strength is the regularization internal force when the first layer plate fails, and the ultimate 


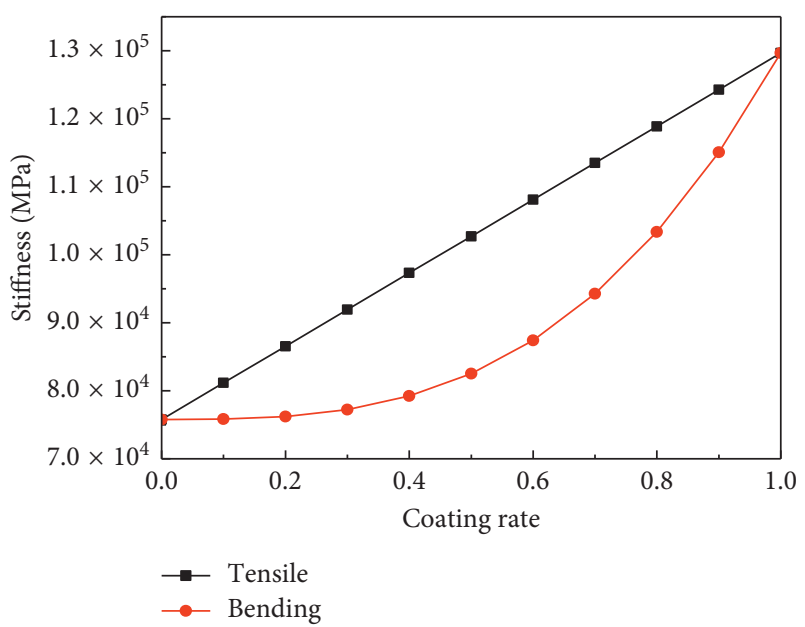

(a)

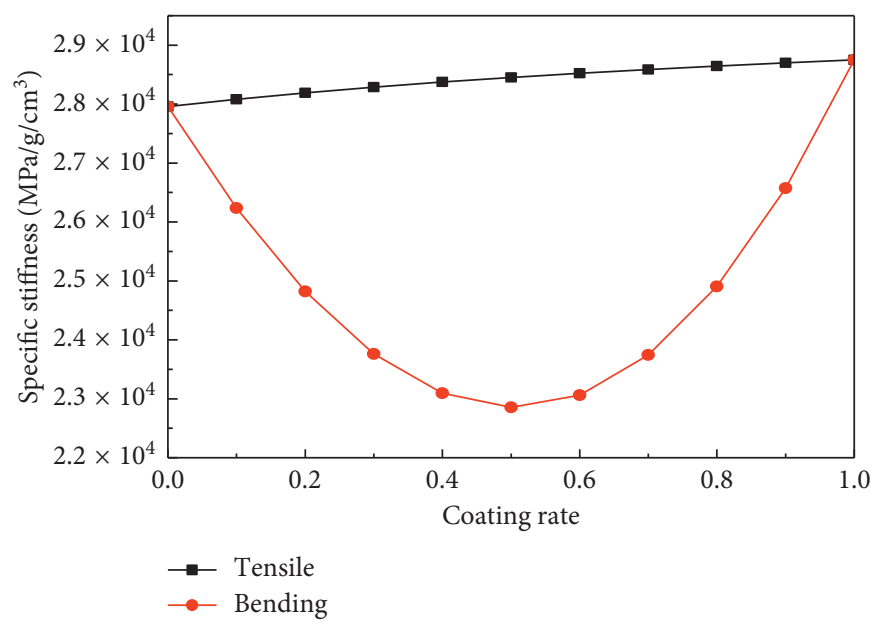

(b)

Figure 2: Stiffness and specific stiffness with the coating rate of Ti. (a) Stiffness of the laminated plate. (b) Specific stiffness of the laminated plate.

strength is the regularization internal force when the laminated plate fails completely [30].

2.2.1. Tensile Strength Calculation of the Laminated Plate. Assume that $N_{x}, N_{y}$, and $N_{x y}$ are the internal force on the unit width (or length) of the cross section of the laminated plate; $M_{x}, M_{y}$, and $M_{x y}$ are the internal torque (bending or torque) on unit width of the cross section of the laminated plate. The stress of the $k$-layer of the laminated plate can be expressed as

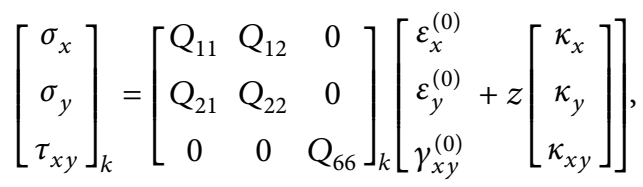

where $[\kappa]$ is the curvature of bending and distorting deformation of the symmetry plane of the middle-layer metal of the laminated plate; $\varepsilon_{i j}^{(0)}$ is the normal and shear strains on the symmetry plane of the middle-layer metal of the laminated plate; $k$ represents the $k$ th layer of the laminated plate, if $k=1$ or $k=3, k$ represents the upper or bottom aluminum alloy layers, and if $k=2, k$ represents the titanium alloy layer; $\left\lfloor Q_{i j}\right\rfloor_{k}$ is the stiffness matrix of the $k$-layer plate; $z$ is the coordinate of the thickness direction of the $k$-layer plate.

The internal forces and internal torques on the laminated plate can be expressed as follows:

$$
\begin{aligned}
& {\left[\begin{array}{c}
N_{x} \\
N_{y} \\
N_{x y}
\end{array}\right]=\int_{-h / 2}^{h / 2}\left[\begin{array}{c}
\sigma_{x} \\
\sigma_{y} \\
\sigma_{x y}
\end{array}\right] \mathrm{d} z=\sum_{k=1}^{n} \int_{Z_{k-1}}^{Z_{k}}\left[\begin{array}{c}
\sigma_{x}^{(k)} \\
\sigma_{y}^{(k)} \\
\tau_{x y}^{(k)}
\end{array}\right] \mathrm{d} z,} \\
& {\left[\begin{array}{c}
M_{x} \\
M_{y} \\
M_{x y}
\end{array}\right]=\int_{-h / 2}^{h / 2}\left[\begin{array}{c}
\sigma_{x} \\
\sigma_{y} \\
\tau_{x y}
\end{array}\right] z \mathrm{~d} z=\sum_{k=1}^{n} \int_{Z_{k-1}}^{Z_{k}}\left[\begin{array}{c}
\sigma_{x}^{(k)} \\
\sigma_{y}^{(k)} \\
\tau_{x y}^{(k)}
\end{array}\right] z \mathrm{~d} z .}
\end{aligned}
$$

The relationship between internal force and strain of the laminated plate can be obtained by integrating formula (6) into formulas (7) and (8).

$$
\begin{aligned}
& {[N]=\left[\varepsilon_{i j}^{(0)}\right] \sum_{k=1}^{n}[Q]_{k}\left(z_{k}-z_{k-1}\right)+\frac{1}{2}[\kappa] \sum_{k=1}^{n}[Q]_{k}\left(z_{k}^{2}-z_{k-1}^{2}\right),} \\
& {[M]=\frac{1}{2}\left[\varepsilon_{i j}^{(0)}\right] \sum_{k=1}^{n}[Q]_{k}\left(z_{k}^{2}-z_{k-1}^{2}\right)+\frac{1}{3}[\kappa] \sum_{k=1}^{n}[Q]_{k}\left(z_{k}^{3}-z_{k-1}^{3}\right) .}
\end{aligned}
$$

Matrix (11) can be obtained by arranging formulas (9) and (10) as follows:

$$
\left[\begin{array}{c}
N_{x} \\
N_{y} \\
N_{x y} \\
\vdots \\
M_{x} \\
M_{y} \\
M_{x y}
\end{array}\right]=\left[\begin{array}{ccccccc}
A_{11} & A_{12} & A_{16} & \cdots & B_{11} & B_{12} & B_{16} \\
A_{21} & A_{22} & A_{26} & \cdots & B_{21} & B_{22} & B_{26} \\
A_{61} & A_{62} & A_{66} & \cdots & B_{61} & B_{62} & B_{66} \\
\vdots & \vdots & \vdots & \ddots & \vdots & \vdots & \vdots \\
B_{11} & B_{12} & B_{16} & \cdots & D_{11} & D_{12} & D_{16} \\
B_{21} & B_{22} & B_{26} & \cdots & D_{21} & D_{22} & D_{26} \\
B_{61} & B_{62} & B_{66} & \cdots & D_{61} & D_{62} & D_{66}
\end{array}\right]\left[\begin{array}{c}
\varepsilon_{x}^{(0)} \\
\varepsilon_{y}^{(0)} \\
\gamma_{x y}^{(0)} \\
\vdots \\
\kappa_{x} \\
\kappa_{y} \\
\kappa_{x y}
\end{array}\right] .
$$

According to the formulas above, the coupling stiffness coefficient of the laminated plate $B_{i j}=0$; then,

$$
\left\{\begin{array}{c}
N_{x}^{*} \\
N_{y}^{*} \\
N_{x y}^{*}
\end{array}\right\}=\left[\begin{array}{ccc}
A_{11}^{*} & A_{12}^{*} & 0 \\
A_{12}^{*} & A_{11}^{*} & 0 \\
0 & 0 & A_{66}^{*}
\end{array}\right]\left\{\begin{array}{c}
\varepsilon_{x}^{(0)} \\
\varepsilon_{y}^{(0)} \\
\gamma_{x y}^{(0)}
\end{array}\right\} .
$$

When only the internal force of the surface is loaded, the deformation curvature of the middle surface of the laminated plate is obtained by formulas (6) and (12): 


$$
\left\{\begin{array}{c}
\sigma_{x} \\
\sigma_{y} \\
\tau_{x y}
\end{array}\right\}_{k}=\left[\begin{array}{ccc}
Q_{11} & Q_{12} & 0 \\
Q_{12} & Q_{11} & 0 \\
0 & 0 & Q_{66}
\end{array}\right]_{k}\left[\begin{array}{ccc}
A_{11}^{*} & A_{12}^{*} & 0 \\
A_{12}^{*} & A_{11}^{*} & 0 \\
0 & 0 & A_{66}^{*}
\end{array}\right]^{-1}\left\{\begin{array}{c}
N_{x}^{*} \\
N_{y}^{*} \\
N_{x y}^{*}
\end{array}\right\}
$$

In order to compare, it is assumed that the laminated plate only bears internal force in the $x$-direction, that is, $N_{y}^{*}=N_{x y}^{*}=0$; formula (13) can be written as

$$
\left\{\begin{array}{l}
\sigma_{x}^{(k)}=\frac{A_{11}^{*} Q_{11}^{(k)}-A_{12}^{*} Q_{12}^{(k)}}{A_{11}^{* 2}-A_{12}^{* 2}} \cdot N_{x}^{*}, \\
\sigma_{y}^{(k)}=\frac{A_{11}^{*} Q_{11}^{(k)}-A_{12}^{*} Q_{12}^{(k)}}{A_{11}^{* 2}-A_{12}^{* 2}} \cdot N_{x}^{*}, \\
\tau_{x y}^{(k)}=0,
\end{array}\right.
$$

where $\sigma_{x}^{(k)}$ is the $x$-direction stress generated by $N_{x}^{*}$ on the $k$ layer of the laminated plate; $\sigma_{y}^{(k)}$ is the $y$-direction stress generated by $N_{x}^{*}$ on the $k$-layer of the laminated plate.

Because of $Q_{11}>Q_{12}$ and $\sigma_{x}>\sigma_{y}$, it is only necessary to check the $x$-direction strength of every single layer. So,

$$
\left\{\begin{array}{l}
\sigma_{x}^{(1)}=\frac{3.68 t+5.22}{2.6 t^{2}+7.38 t+5.22} \cdot N_{x}^{*} \\
\sigma_{x}^{(2)}=\frac{6.29 t+5.91}{2.6 t^{2}+7.38 t+5.22} \cdot N_{x}^{*}
\end{array}\right.
$$

where $\sigma_{x}^{(1)}$ and $\sigma_{x}^{(2)}$ represent the tensile stress of $\mathrm{Ti}$ and $\mathrm{Al}$, under the action of external force.

When the laminated plate is being subjected to $N_{x}^{*}$, the tensile safety coefficients $R_{1}$ and $R_{2}$ of the titanium layer and aluminum layer are as follows:

$$
\left\{\begin{array}{l}
R_{1}=\frac{R_{e}^{(1)}}{\sigma_{x}^{(1)}} \\
R_{2}=\frac{R_{e}^{(2)}}{\sigma_{x}^{(2)}} .
\end{array}\right.
$$

Figure 3 shows the tensile safety coefficients of the laminated plate. In order to compare the safety coefficients of the two metals, assume that the regularized internal force $N_{x}^{*}$ is equal to the yield strength of the aluminum alloy. It can be seen from Figure 3 that the tensile safety coefficient of the laminated plate increases with the increase of the coating rate of titanium alloy, and the safety coefficient of the titanium alloy layer is always greater than that of the aluminum alloy layer. It can be concluded that the aluminum alloy layer of the laminated plate always fails first under the action of the inner pulling force. Therefore, the tensile failure intensity of the laminated plate can be expressed by the following formula:

$$
\sigma_{s}=\frac{2.6 t^{2}+7.38 t+5.22}{3.68 t+5.22} \cdot R_{e}^{(1)} .
$$

\subsubsection{Bending Strength Calculation of the Laminated Plate.} The calculation process of the bending strength of the laminated plate is similar to that of tensile strength calculation. When the laminated plate only bears internal torque, $\left[\varepsilon_{i j}^{(0)}\right]=0$, formula (11) can be written as

$$
\left\{\begin{array}{l}
M_{x}^{*} \\
M_{y}^{*} \\
M_{x y}^{*}
\end{array}\right\}=\left[\begin{array}{ccc}
D_{11}^{*} & D_{12}^{*} & 0 \\
D_{12}^{*} & D_{11}^{*} & 0 \\
0 & 0 & D_{66}^{*}
\end{array}\right]\left\{\begin{array}{c}
\kappa_{x}^{*} \\
\kappa_{y}^{*} \\
\kappa_{x y}^{*}
\end{array}\right\}
$$

When the laminated plate only bears internal torque $\{M\}$, the central strain of the laminated plate is 0 , which can be obtained from formulas (6) and (18).

$$
\left\{\begin{array}{c}
\sigma_{x} \\
\sigma_{y} \\
\tau_{x y}
\end{array}\right\}_{k}=z^{*}\left[\begin{array}{ccc}
Q_{11} & Q_{12} & 0 \\
Q_{12} & Q_{22} & 0 \\
0 & 0 & Q_{66}
\end{array}\right]_{k}\left[\begin{array}{ccc}
D_{11}^{*} & D_{12}^{*} & 0 \\
D_{12}^{*} & D_{11}^{*} & 0 \\
0 & 0 & D_{66}^{*}
\end{array}\right]^{-1}\left\{\begin{array}{c}
M_{x}^{*} \\
M_{y}^{*} \\
M_{x y}^{*}
\end{array}\right\} .
$$

In the same way, it is assumed that the laminated plate only bears internal torque in the $x$-direction; formula (19) can be written as

$$
\left\{\sigma_{x}^{\prime(k)}=z^{*} \cdot \frac{D_{11}^{*} Q_{11}^{(k)}-D_{12}^{*} Q_{12}^{(k)}}{D_{11}^{* 2}-D_{12}^{* 2}} \cdot M_{x}^{*}, \sigma_{y}^{\prime(k)}=z^{*} \cdot \frac{D_{11}^{*} Q_{12}^{(k)}-D_{12}^{*} Q_{11}^{(k)}}{D_{11}^{* 2}-D_{12}^{* 2}} \cdot M_{x}^{*}, \tau_{x y}^{\prime(k)}=0,\right.
$$

where $\sigma_{x}^{\prime(k)}$ represents the $x$-direction stress on the bottom surface of the $k$-layer of the laminated plate; $\sigma_{y}^{\prime(k)}$ represents the $y$-direction stress on the bottom surface of the $k$-layer of the laminated plate.

In the same way, it is only necessary to check the $x$ direction strength of every single layer. So,

$$
\left\{\begin{array}{l}
\sigma_{x}^{\prime(1)}=\frac{3.68 t^{3}+5.22}{2.6 t^{6}+7.38 t^{3}+5.22} \cdot M_{x}^{*} \\
\sigma_{x}^{\prime(2)}=\frac{6.29 t^{4}+5.91 t}{2.6 t^{6}+7.38 t^{3}+5.22} \cdot M_{x}^{*}
\end{array}\right.
$$




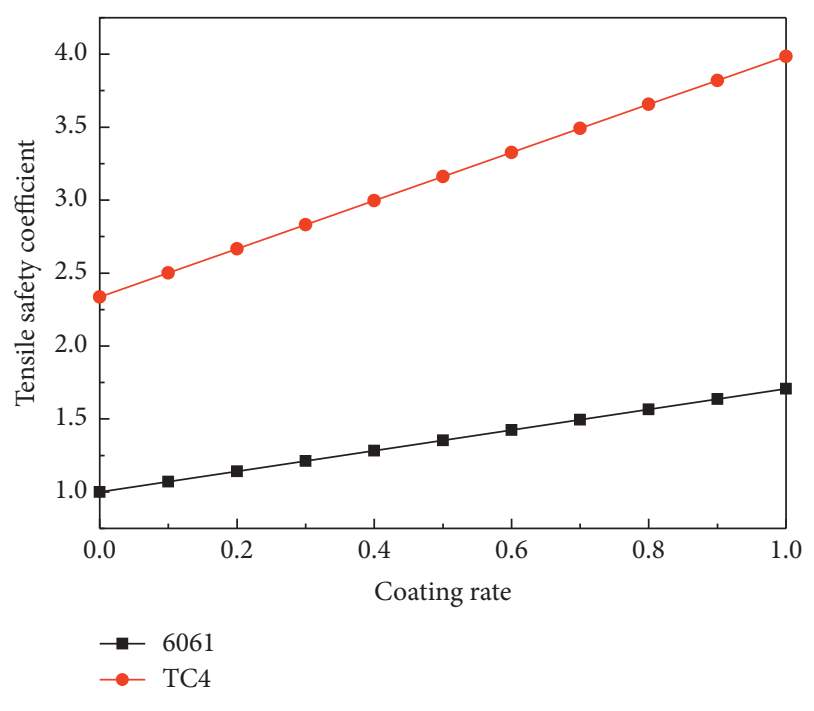

Figure 3: Tensile safety coefficients.

Similarly, the bending safety coefficient of the titanium layer and the aluminum layer can be obtained by formula (16), and the results are shown in Figure 4.

As can be seen from Figure 4, with the increase of the coating rate of the titanium alloy, the bending safety coefficient of the titanium plate decreases, but the bending safety coefficient of the aluminum plate remains basically unchanged. Since, under the action of the inner torque, the bending safety coefficient of the titanium plate is always higher than that of the aluminum plate, the aluminum alloy layer of the laminated plate always fails first. Therefore, the bending yield strength of the Al-Ti-Al laminated plate can be expressed as the following formula:

$$
\sigma_{s}^{\prime}=\frac{2.6 t^{6}+7.38 t^{3}+5.22}{3.68 t^{3}+5.22} \cdot R_{e}^{(1)} .
$$

Through the analysis of formulas (17) and (22), it can be seen that the strength of the whole laminated plate is closely related to the thickness of the titanium layer which directly affects the properties of the whole laminated plate. The failure strength and specific strength of the Al-Ti-Al laminated plate with the coating rate of titanium alloy are shown in Figure 5.

As can be seen from Figure 5(a), with the increase of the coating rate of titanium, the tensile strength of the laminated plate increases linearly, and the curve of bending strength is parabolic. It can be seen from Figure 5(b) that the tensile specific strength increases slowly with the increase of coating rate of titanium, but the bending specific strength of the laminated plate decreases at first and then rises. The inflection point of bending specific strength appears when the coating rate of titanium alloy TC4 is 0.5 .

Through the analysis of the results of specific stiffness and specific strength, it can be found that the trends of specific strength and specific stiffness of the laminated plate are basically similar. When the coating rate of titanium alloy is 0.5 , the bending specific stiffness and bending specific strength of the laminated plate are the smallest. Therefore, in actual production, the coating rate of titanium alloy should be avoided being 0.5 .

\section{Rolling Experiment of the Al-Ti-Al Laminated Plate}

The rolling experiments of the Al-Ti-Al laminated plate were carried out with different temperatures, reduction rates, and thickness ratios.

3.1. Experimental Materials. The experimental research objects were aluminum alloy 6061 and titanium alloy TC4, the base layer material was titanium alloy TC4, and the composite material was aluminum alloy 6061. The main components of the experimental materials were shown in Tables 2 and 3 .

3.2. Rolling Experiment. The rolling experiments of the laminated plate were carried out on the two-roller experimental rolling mill of the laboratory; the specific process of laminated plate hot rolling experiments is shown in Figure 6. The method comprised the following steps: firstly, in order to ensure the bonding strength of the laminated plate, carrying out surface treatment on the composite surface of the metal plate, secondly, riveting the three-layer metal plate, then heating and rolling the laminated plate according to the rolling schedule, and finally, carrying out heat treatment on the laminated plate. The main parameters of the rolling mill are shown in Table 4.

Figure 7 shows the laminated plate before and after rolling. The length of the metal plates was $200 \mathrm{~mm}$, and the width of the metal plates was $100 \mathrm{~mm}$. The other rolling parameters of the laminated plate are set as shown in Table 5. In order to ensure the strength and stiffness of the laminated plate according to the previous theoretical analysis, it was necessary to avoid the case when the coating rate of the titanium alloy was 0.5 . Therefore, $0.2,025$, and 0.33 were, respectively, adopted as the coating rate of the titanium alloy in the rolling experiment. For rolling temperatures, when the rolling temperature is too low, it is not good for metal plastic to play, and deformation resistance and rolling force are too large; however, aluminum alloy is easy to generate crack when it is subjected to large deformation force, so rolling composite cannot be achieved. When the temperature is too high, the surface oxidation of titanium alloy is serious, and plate warping deformation is also relatively large. To sum up, the suitable rolling temperature is $300-450^{\circ} \mathrm{C}$. The annealing temperature after rolling selection is a critical point for the appearance of brittle intermetallic compounds, and the suitable temperature for annealing is $380-580^{\circ} \mathrm{C}$ [31]. Therefore, $350^{\circ} \mathrm{C}, 400^{\circ} \mathrm{C}$, and $450^{\circ} \mathrm{C}$ were, respectively, adopted as the rolling temperature in the rolling experiment.

As can be seen from Table 5, the thickness of the actual rolled laminated plate was larger than that of the calculated one according to the reduction rate. The main reasons were as follows: the stiffness of the rolling mill was not high enough, and the deformation resistance of titanium alloy between $350^{\circ} \mathrm{C}$ and $450^{\circ} \mathrm{C}$ and the bouncing capacity of the rolling mill were large, so the error between the actual thickness after rolling and the calculated value was large. When the rolling parameters were as S2, the three metal layers cannot roll 


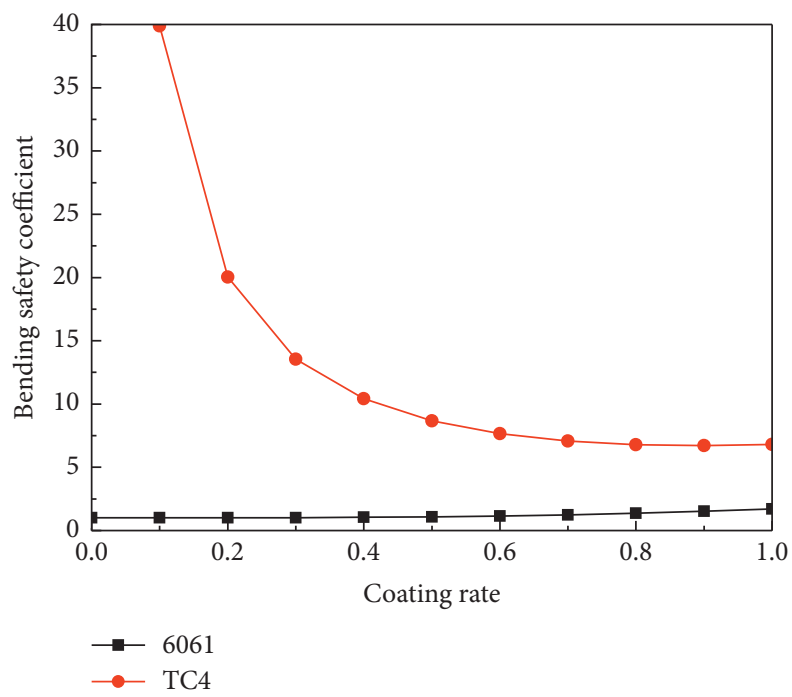

FIGURE 4: The bending safety coefficient.

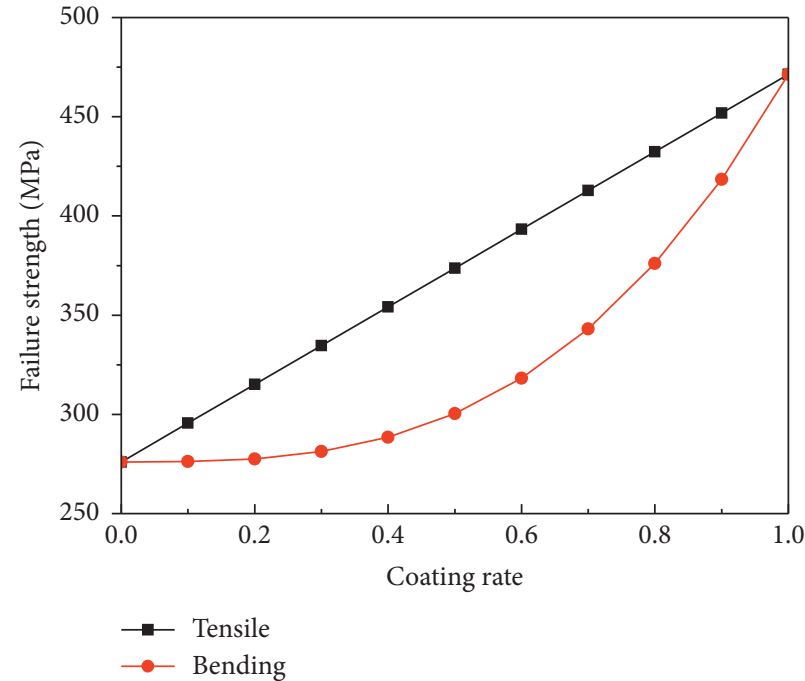

(a)

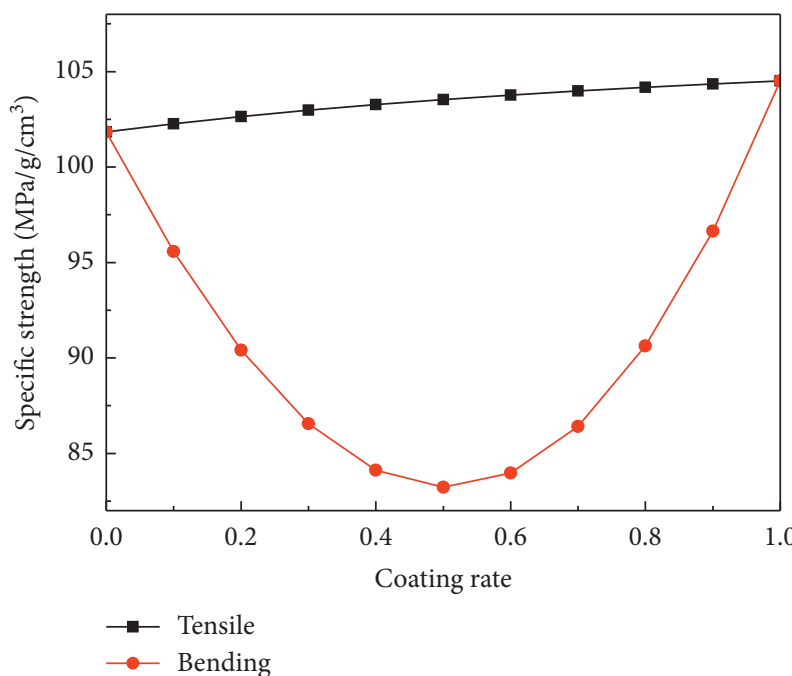

(b)

FIGURE 5: Failure strength and specific strength with the coating rate of Ti. (a) Failure strength of the laminated plate. (b) Specific strength of the laminated plate.

TABLE 2: Main components of titanium alloy TC4.

\begin{tabular}{ccccccccc}
\hline & $\mathrm{Al}$ & $\mathrm{V}$ & $\mathrm{Fe}$ & $\mathrm{C}$ & $\mathrm{N}$ & $\mathrm{H}$ & $\mathrm{O}$ & Others \\
\hline TC4 & $6.3 \sim 6.4$ & 4.2 & $0.15 \sim 0.17$ & 0.01 & 0.01 & 0.007 & 0.15 & 0.10 \\
\hline
\end{tabular}

TABle 3: Main components of aluminum alloy 6061.

\begin{tabular}{cccccccccc}
\hline & $\mathrm{Si}$ & $\mathrm{Fe}$ & $\mathrm{Cu}$ & $\mathrm{Mn}$ & $\mathrm{Mg}$ & $\mathrm{Cr}$ & $\mathrm{Zn}$ & $\mathrm{Ti}$ & Others \\
\hline 6061 & $0.4 \sim 0.8$ & $<0.7$ & $0.15 \sim 0.4$ & $<0.15$ & $0.8 \sim 1.2$ & $0.04 \sim 0.35$ & $<0.25$ & $<0.15$ & $<0.05$ \\
\hline
\end{tabular}

together, because serious oxygen absorption occurred in a titanium plate, and a dense oxide film was formed on the surface of the titanium plate at $400^{\circ} \mathrm{C}$; moreover, the coating rate of TC4 and reduction rate were relatively small.

\section{Mechanical Properties of the Laminated Plate}

In order to analyze the effect of rolling process parameters on the mechanical properties of the laminated plate, the 


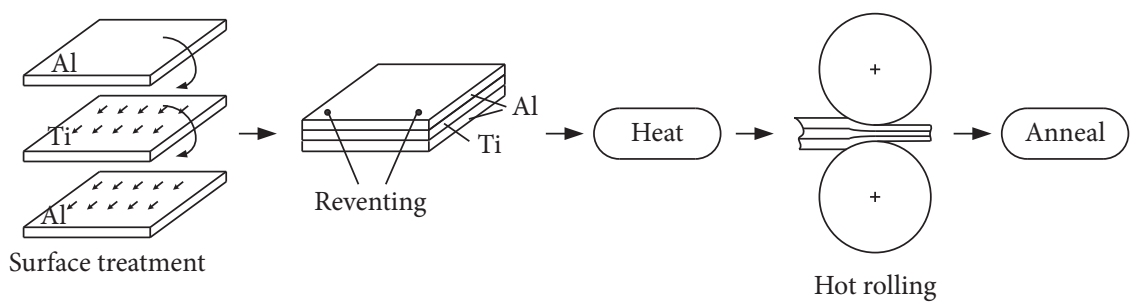

FIgure 6: The specific process of hot rolling.

TABle 4: Performance parameters of the two-roll mill.

\begin{tabular}{lcccc}
\hline Roller size & Motor capacity $(\mathrm{kW})$ & Motor speed & Max rolling force $(\mathrm{kN})$ & Max rolling speed \\
\hline$\Phi 320 \times 350 \mathrm{~mm}$ & 90 & $1500 \sim 2000 \mathrm{r} / \mathrm{min}$ & 1500 & $2 \mathrm{~m} / \mathrm{s}$ \\
\hline
\end{tabular}

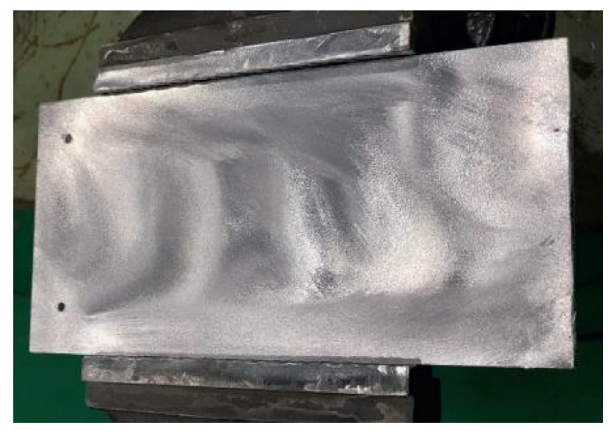

(a)

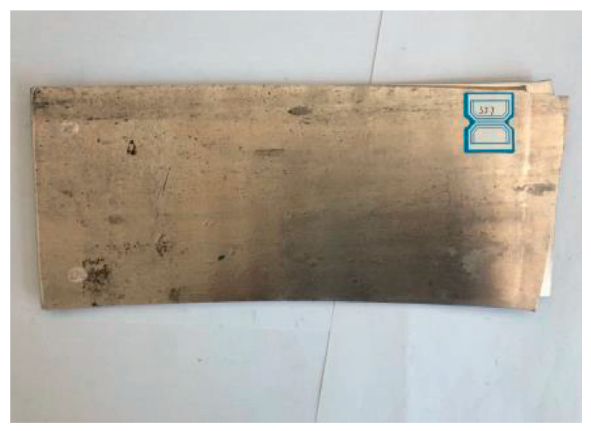

(b)

Figure 7: The Al-Ti-Al laminated plate. (a) Before rolling. (b) After rolling.

TABLE 5: Rolling parameters of the laminated plate.

\begin{tabular}{|c|c|c|c|c|c|c|c|}
\hline No. & $\begin{array}{l}\text { Thickness of TC4 } \\
(\mathrm{mm})\end{array}$ & $\begin{array}{l}\text { Coating rate } \\
\text { of TC4 }\end{array}$ & $\begin{array}{l}\text { Total thickness } \\
(\mathrm{mm})\end{array}$ & $\begin{array}{c}\text { Rolling } \\
\text { temperature }\left({ }^{\circ} \mathrm{C}\right)\end{array}$ & $\begin{array}{c}\text { Reduction rate } \\
(\%)\end{array}$ & $\begin{array}{c}\text { Theoretical } \\
\text { thickness }(\mathrm{mm})\end{array}$ & $\begin{array}{c}\text { Thickness after } \\
\text { rolling }(\mathrm{mm})\end{array}$ \\
\hline S1 & 1 & 0.2 & 5 & 350 & 40 & 3 & 4 \\
\hline S2 & 1 & 0.2 & 5 & 400 & 40 & 3 & - \\
\hline S3 & 1 & 0.2 & 5 & 450 & 40 & 3 & 4.1 \\
\hline S4 & 1 & 0.2 & 5 & 400 & 50 & 2.5 & 3.1 \\
\hline S5 & 1 & 0.25 & 4 & 400 & 40 & 2.4 & 3.3 \\
\hline S6 & 1 & 0.33 & 3 & 400 & 40 & 1.8 & 2.6 \\
\hline
\end{tabular}

tensile test and energy spectrum analysis of the laminated plates were carried out in this paper.

4.1. Tensile Test. The rolled laminated plates were subjected to the WDW-200E universal testing machine to test their mechanical properties. According to the relevant standards, the specific sizes of the tensile specimens with different thicknesses are shown in Figure 8.

Figure 9 shows the stress-strain curves at different rolling temperatures; Figure 10 shows the stress-strain curves at different thickness ratios. From Figure 9, the tensile strength of S3 was $312 \mathrm{MPa}$ and the extensibility was $10 \%$, while the tensile strength of S1 was $209 \mathrm{MPa}$ and the extensibility was only $7 \%$. The temperature had an obvious effect on the bonding properties of the laminated plate; with the increase of temperature, the tensile strength and the extensibility increased. As shown in Figure 10, the tensile strength of S5 was $490 \mathrm{MPa}$ and the extensibility was $13 \%$, while the tensile strength of S6 was $513 \mathrm{MPa}$ and the extensibility was $16 \%$. It indicated that the bonding strength of the laminated plate increased with the increase of the coating rate of the titanium alloy when the other rolling process parameters were the same.

4.2. Energy Spectrum Experiment. In order to analyze the thickness of the bonding interface diffusion layers, the laminated plates were cut and polished by sandpaper and polishing machines. Then, the laminated plates were tested by SEM at 1000 times magnification.

Figure 11(a) shows the morphology and energy spectrum of S1 and Figure 11(b) shows that of S3. From Figure 11, we knew that the thickness diffusion layer of TC4 and 6061 of S1 was $2 \sim 4 \mu \mathrm{m}$, and that of S3 was $4 \sim 8 \mu \mathrm{m}$. We can see that both sides of the junction surface of TC4 and 6061 


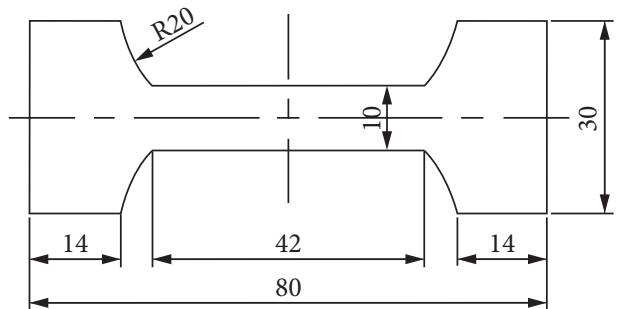

(a)

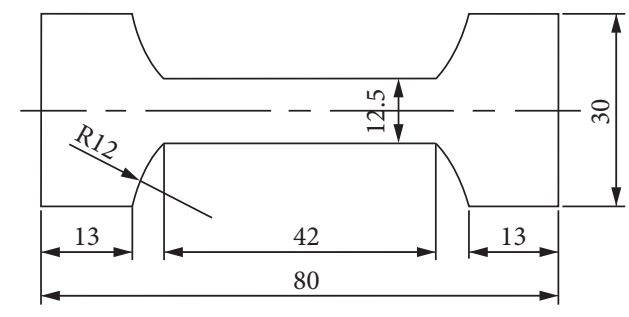

(b)

Figure 8: Dimensions of tensile specimens. (a) Thickness less than $3 \mathrm{~mm}$. (b) Thickness greater than $3 \mathrm{~mm}$.

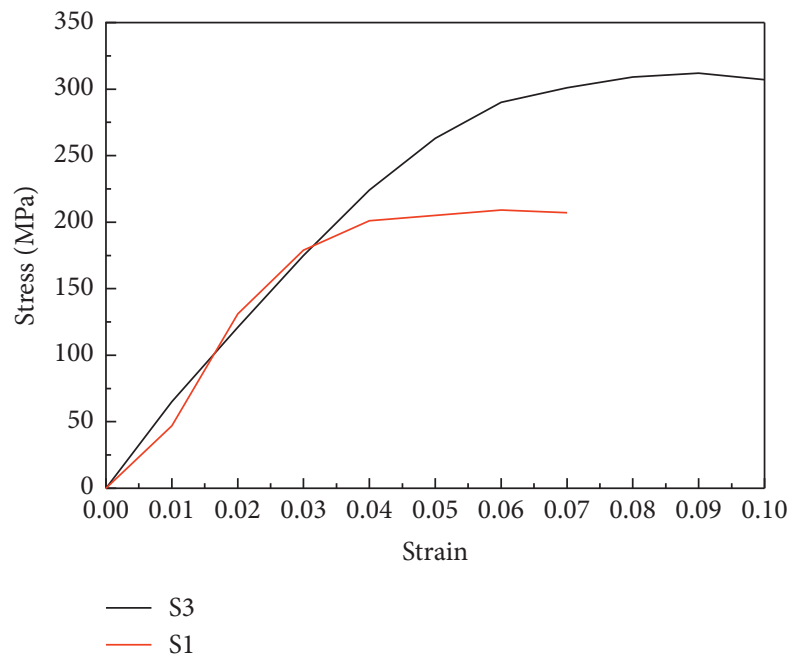

FIgURE 9: Stress-strain curves at different temperatures for the same reduction rate.

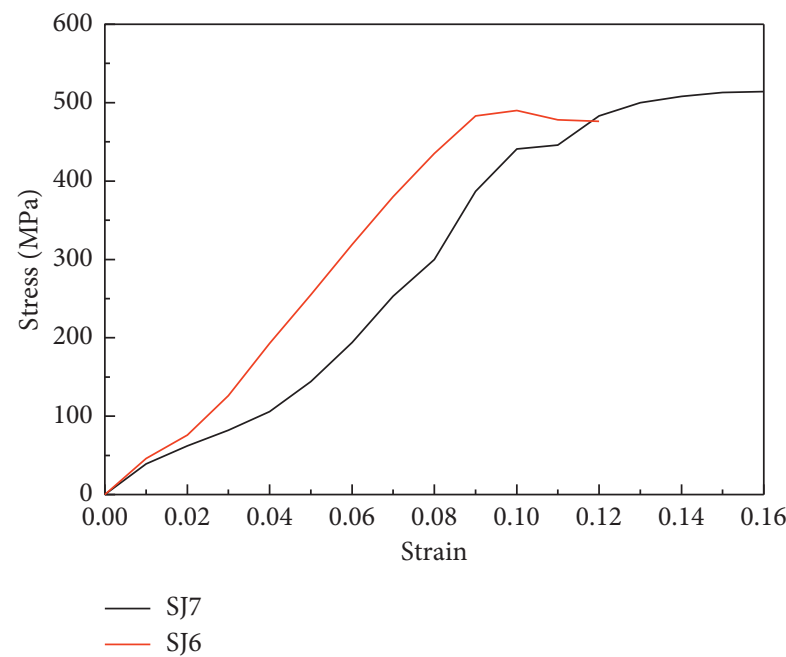

FIGURE 10: Stress-strain curves at different thickness ratios.

had been successfully combined, but there were some cracks in the junction surfaces; with the increase of temperature, the thickness of diffusion layers increased; it was because the higher the rolling temperature was, the faster the metal atom moved, and the greater the range of atomic migration caused by thermal diffusion, the greater the thickness of the diffusion layer. And it verified the theoretical calculation and tensile test results.

Figure 12 shows the morphology and energy spectrum of S4. From Figure 12, it can be seen that both interfaces of S4 formed good and uniform composite interfaces, and the thickness of both diffusion layers was $5 \sim 6 \mu \mathrm{m}$. Compared with $S 1$ and S3, higher rolling temperature and reduction rate were adopted in S4; under the combined action of the two factors, the performance of S4 was significantly better than that of S1 and S3.

Figure 13(a) shows the morphology and energy spectrum of S5 and Figure 13(b) shows that of S6. From Figure 13, it can be concluded that both S5 and S6 had good composite interfaces, and the thickness difference between the two diffusion layers was only about $1 \mu \mathrm{m}$. The main factor affecting the mechanical properties of S5 and S6 was the different thicknesses of the TC4.

As can be seen from Figure 13, S6 had good composite interfaces and no obvious cracks, but there was a crack on the interface of $S 5$, which affected the mechanical properties of S5 and also made the performance of S5 worse than that of S6 in the process of tensile test. Through the comparison of the spectrum analysis of S5 and S6, it can be concluded that with the increase of the coating rate of the titanium plate, the mechanical properties and the bonding strength of the laminated plate increased. 


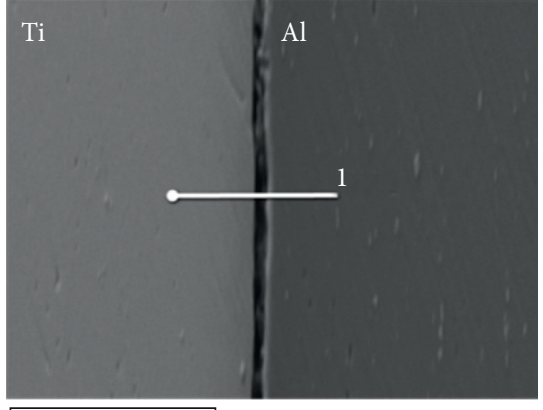

$100 \mu \mathrm{m}$
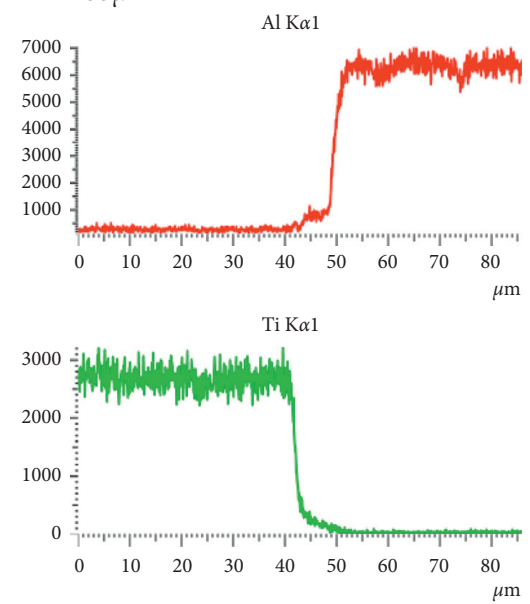

(a)

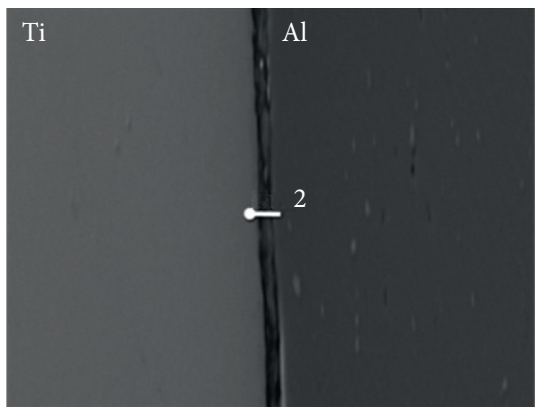

$100 \mu \mathrm{m}$

$\mathrm{Al} \mathrm{K} \alpha 1$
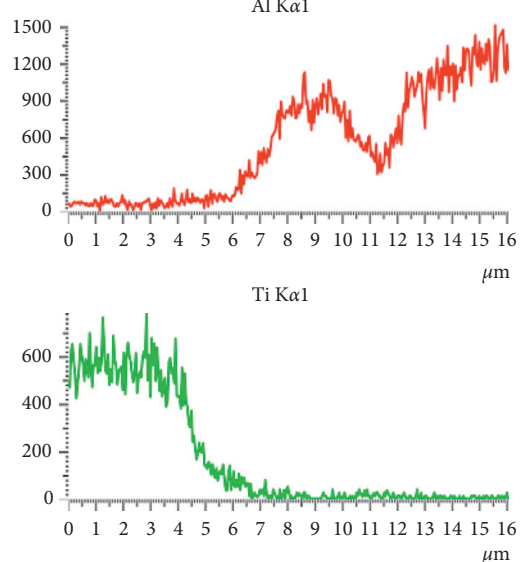
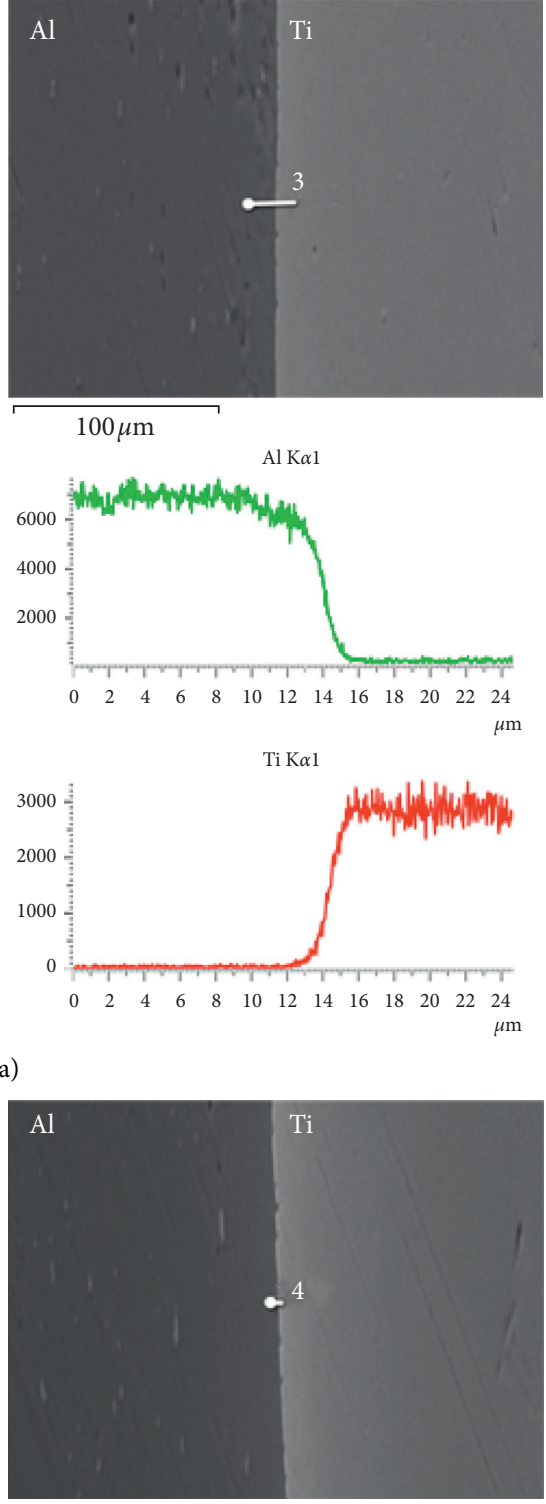

$100 \mu \mathrm{m}$
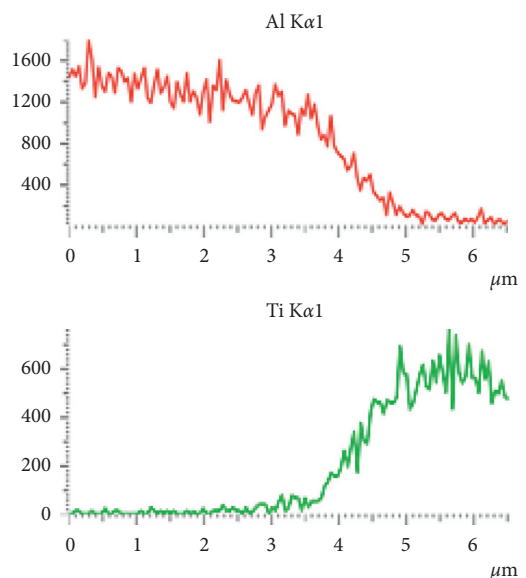

(b)

Figure 11: The morphology and energy spectrum of (a) S1 and (b) S3. 

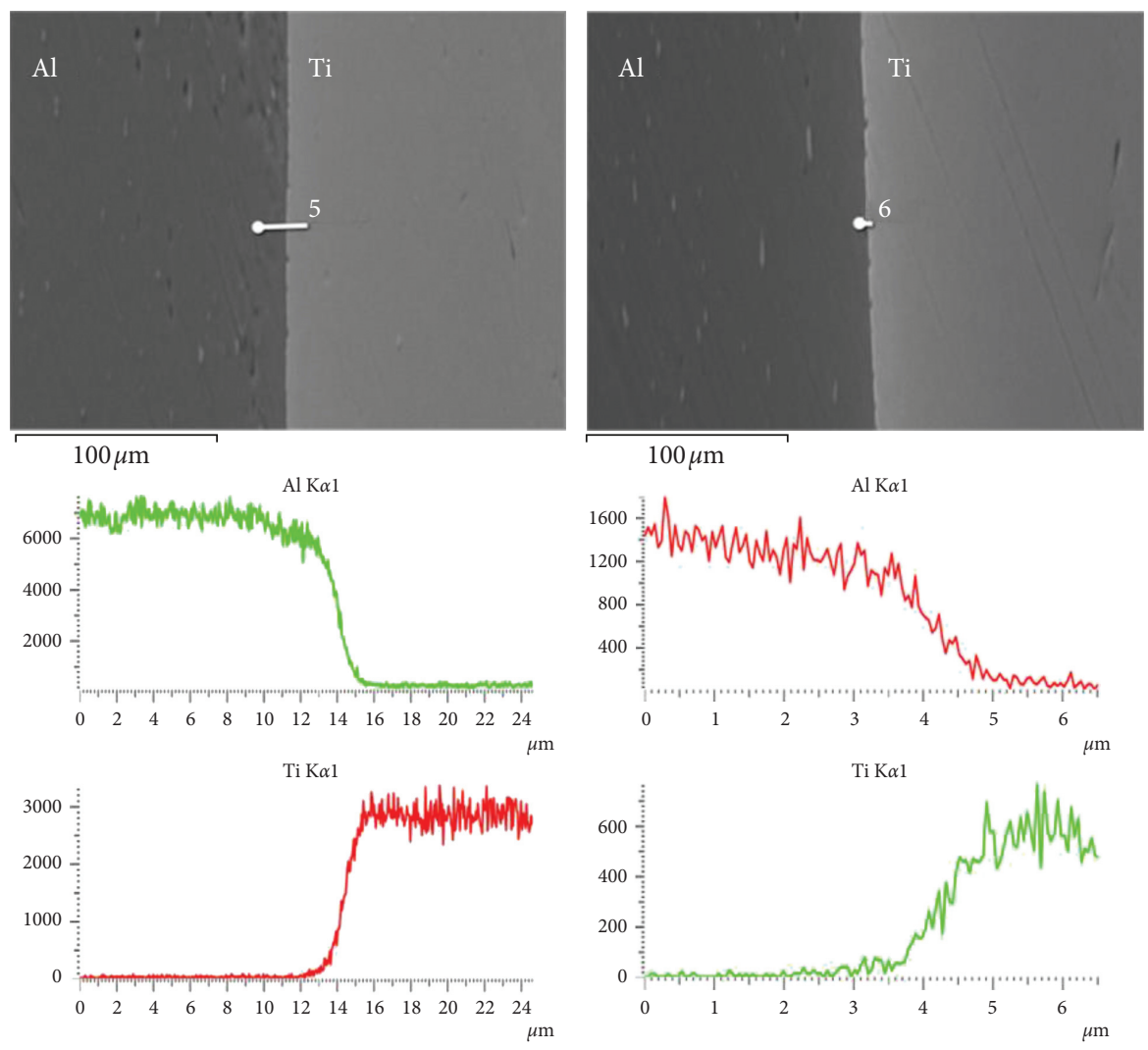

FIgURE 12: The morphology and the energy spectrum of S4.
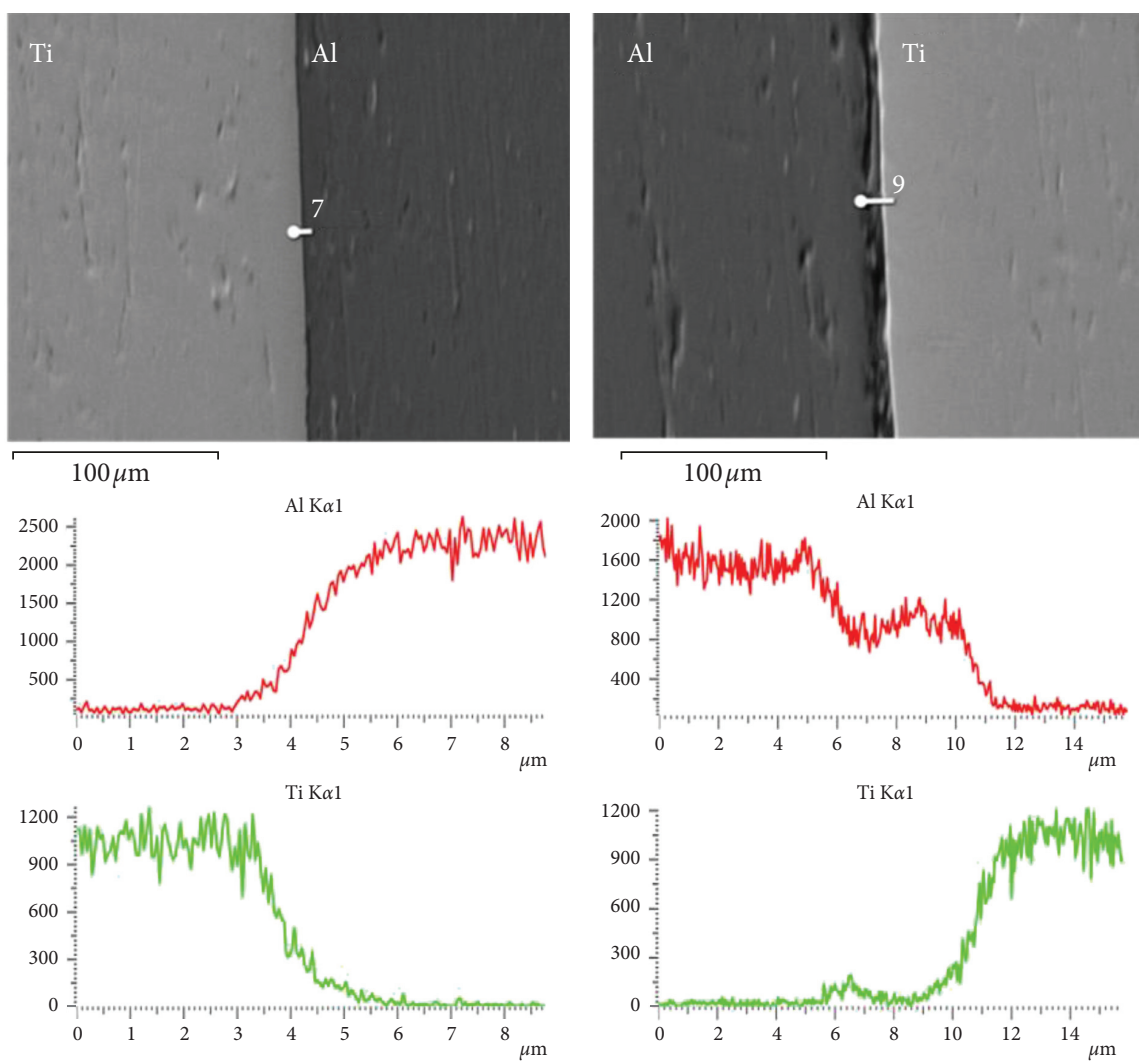

(a)

Figure 13: Continued. 

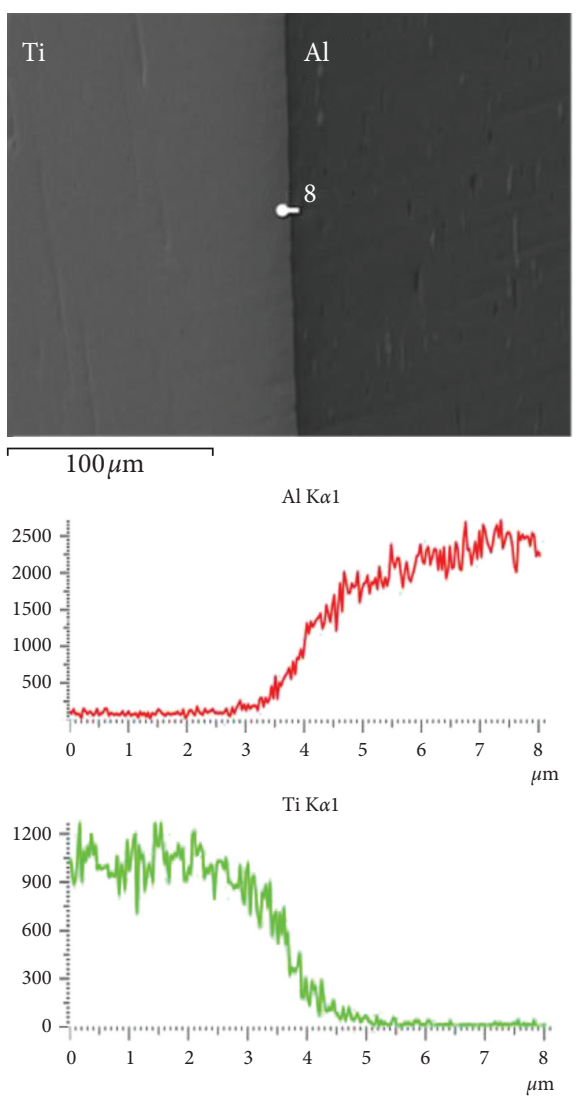

(b)
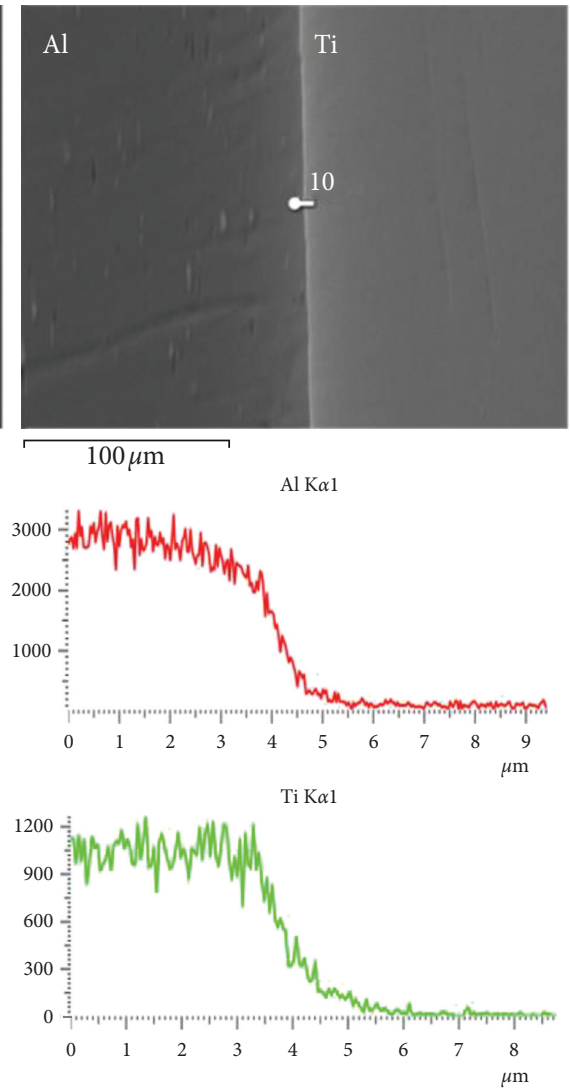

FIgURE 13: The morphology and the energy spectrum of (a) S5 and (b) S6.

\section{Conclusion}

(1) According to the theoretical calculation results, with the increase of coating rate of titanium alloy TC4, all parameters except the bending specific stiffness and bending specific strength of Al-Ti-Al symmetrical laminated plate increased; when the coating rate of titanium alloy TC4 was 0.5 , bending specific stiffness and bending specific strength were the minimum. Therefore, in order to improve the performance of laminated plates and reduce the cost, in actual production, the coating rate of titanium alloy should be less than 0.5 .

(2) According to the experimental results, with the increase of rolling temperature, the tensile strength, the extensibility, and the thickness of diffusion layer increased; if the coating rate of the titanium alloy TC4 was from 0.2 to 0.33 , the mechanical properties and the bonding strength of the laminated plate increased with the increase of the coating rate.

\section{Data Availability}

The origin data used to support the findings of this study are included within the article.

\section{Conflicts of Interest}

The authors declare that they have no conflicts of interest.

\section{Acknowledgments}

This work was sponsored by the National Natural Science Foundation of China (51504157), China Postdoctoral Science Foundation (2016M601288 and 20172010), Shanxi Province Science and Technology Major Special Project (20181102015), and Graduate Education Innovation Project of Shanxi Province (2018JD32). All these are gratefully appreciated.

\section{References}

[1] H. T. M. Nu, T. T. Le, L. P. Minh, and N. H. Lo, "A study on rotary friction welding of titanium alloy (Ti6Al4V)," Advances in Materials Science and Engineering, vol. 2019, Article ID 4728213, 9 pages, 2019.

[2] L. P. Lefebvre and E. Baril, "Properties of titanium foams for biomedical applications," Advanced Engineering Materials, vol. 15, pp. 32-39, 2013.

[3] X. G. Fan, H. Yang, P. F. Gao, and S. L. Yan, "Dependence of microstructure morphology on processing in subtransus isothermal local loading forming of TA15 titanium alloy," Materials Science and Engineering: A, vol. 546, pp. 46-52, 2012.

[4] G. C. Weatherly, A. Perovic, D. D. Perovic, N. K. Mukhopadhyay, and D. J. Lloyd, "The precipitation of the Q phase in an AA6111 alloy," Metallurgical and Materials Transactions A, vol. 32, no. 2, pp. 213-218, 2001. 
[5] J. Zang, S. R. Yu, G. Zhu, and X. Zhou, "Fabrication of superhydrophobic surface on aluminum alloy 6061 by a facile and effective anodic oxidation method," Surface \& Coatings Technology, vol. 380, Article ID 125078, 2019.

[6] Y. Wang and Z. Wang, "Experimental investigation and FE analysis on constitutive relationship of high strength aluminum alloy under cyclic loading," Advances in Materials Science and Engineering, vol. 2016, Article ID 2941874, 16 pages, 2016.

[7] Z. J. Chen and Q. Z. Chen, "Interface shear actions and mechanical properties of nanostructured dissimilar Al alloy laminated metal composites," Journal of Nanomaterials, vol. 2015, Article ID 612029, 14 pages, 2015.

[8] A. Macwan, X. Q. Jiang, C. Li, and D. L. Chen, "Effect of annealing on interface microstructures and tensile properties of rolled $\mathrm{Al} / \mathrm{Mg} / \mathrm{Al}$ tri-layer clad sheets," Materials Science and Engineering: A, vol. 587, pp. 344-351, 2013.

[9] K. S. Lee, Y. S. Lee, and Y. N. Kwon, "Influence of secondary warm rolling on the interface microstructure and mechanical properties of a roll-bonded three-ply $\mathrm{Al} / \mathrm{Mg} / \mathrm{Al}$ sheet," $M a$ terials Science and Engineering: A, vol. 606, pp. 205-213, 2014.

[10] S. S. Seyyed Afghahi, M. Jafarian, M. Paidar, and M. Jafarian, "Diffusion bonding of $\mathrm{Al} 7075$ and Mg AZ31 alloys: process parameters, microstructural analysis and mechanical properties," Transactions of Nonferrous Metals Society of China, vol. 26, no. 7, pp. 1-10, 2016.

[11] X. P. Zhang, T. H. Yang, S. Castagne, and J. T. Wang, "Microstructure, bonding strength and thickness ratio of $\mathrm{Al} /$ $\mathrm{Mg} / \mathrm{Al}$ alloy laminated composites prepared by hot rolling," Materials Science and Engineering: A, vol. 528, no. 4-5, pp. 1954-1960, 2011.

[12] D. F. Mo, T. F. Song, Y. J. Fang et al., "A review on diffusion bonding between titanium alloys and stainless steels," $A d$ vances in Materials Science and Engineering, vol. 2018, Article ID 8701890, 15 pages, 2018.

[13] S. Y. Gu, H. M. Fang, Z. C. Zhou, and J. Du, "Thee volution of microstructure and mechanical properties of Ti/Al composite synthesized by accumulative roll-bonding," Acta Physica Sinica, vol. 61, no. 18, Article ID 186104, 2012.

[14] W. Xu, M. Zhu, S. L. Guo, J. Hu, and D. F. Li, "Interfacial microstructure of Ti-Al composite plate and it effect on processing properties," Chinese Journal of Rare Metals, vol. 35, no. 3, pp. 342-348, 2011, in Chinese.

[15] Q. Q. Jia, D. Y. Li, S. Guan, Z. Zhang, N. N. Zhang, and W. Z. Zhao, "Oxidation resistance and modification reaction mechanism of Al coating sprayed on pure Ti substrate," Advances in Materials Science and Engineering, vol. 2018, Article ID 1403521, 9 pages, 2018.

[16] Z. J. Chen, Q. Z. Chen, G. J. Huang, and X. F. Liu, "Research on roll bonding technology and microstructure of $\mathrm{Al} / \mathrm{Ti} / \mathrm{Al}$ three-layer clad sheet fabricated by hot rolling," Materials Report B, vol. 26, no. 3, pp. 106-109, 2016, in Chinese.

[17] H. B. Xia, S. G. Wang, and H. F. Ben, "Microstructure and mechanical properties of composite plate between pure titanium and aluminum alloy with explosive welding," Pressure Vessel Technology, vol. 8, pp. 15-20, 2013, in Chinese.

[18] W. Y. Wang, S. Q. Shi, Z. P. Shang et al., "Interfacial microstructyre and properties of Ti- Al rolling-casted composite plate," Special-cast and Non-ferrous Alloys, vol. 10, pp. 1084-1088, 2016, in Chinese.

[19] J. G. Luo and V. L. Acoff, "Using cold roll bonding and annealing to process Ti/Al multi-layered composites from elemental foils," Materials Science and Engineering: A, vol. 379, no. 1-2, pp. 164-172, 2004.
[20] X. Z. Guo, J. Tao, Z. Yuan, L. W. Zhang, and X. J. Sun, "Interface and properties of explosive welded TA1/Al clad tube," Rare Metal Materials and Engineering, vol. 41, no. 1, pp. 139-142, 2012.

[21] I. A. Bataev, A. A. Bataev, V. I. Mali, and D. V. Pavliukova, "Structural and mechanical properties of metallic-intermetallic laminate composites produced by explosive welding and annealing," Materials \& Design, vol. 35, no. 30, pp. 225-234, 2012.

[22] Z. X. Ma, D. F. Li, J. Hu, and Y. L. Li, "Process of explosive welding-rolling for preparation of Titanium/Aluminum composite plate," Chinese Journal of Rare Metals, vol. 28, no. 4, pp. 797-799, 2004, in Chinese.

[23] M. Ma, X. Meng, W. C. Liu, G. J. Wang, and D. M. Wang, "Microstructure and mechanical properties of Ti/Al/Ti laminated composites prepared by hot rolling," Journal of $M a$ terials Engineering and Performance, vol. 26, no. 7, pp. 3569-3578, 2017.

[24] M. Ma, P. Huo, and W. C. Liu, "Microstructure and mechanical properties of $\mathrm{Al} / \mathrm{Ti} / \mathrm{Al}$ laminated composites prepared by roll bonding," Materials Science \& Engineering A, vol. 636, pp. 301-310, 2015.

[25] H. L. Yu, C. Lu, A. Kiet Tieu, H. J. Li, A. Godbole, and C. Kong, "Annealing effect on microstructure and mechanical properties of $\mathrm{Al} / \mathrm{Ti} / \mathrm{Al}$ laminate sheets," Materials Science \& Engineering A, vol. 660, pp. 195-204, 2016.

[26] Y. Mi, H. Nie, T. Wang, X. Li, X. Hao, and W. Liang, "Effect of anisotropy on microstructures and mechanical properties of rolled Ti/Al/Mg/Al/Ti laminates," Journal of Materials Engineering and Performance, vol. 28, no. 7, pp. 4143-4151, 2019.

[27] D. M. Fronczek, J. Wojewoda-Budka, R. Chulist et al., "Structural properties of Ti/Al clads manufactured by explosive welding and annealing," Materials \& Design, vol. 91, pp. 80-89, 2016.

[28] R. Jafari and B. Eghbali, "Influence of $\mathrm{Nb}$ and $\mathrm{Cu}$ elements on the intermetallic particles morphology in $\mathrm{Ti} / \mathrm{Al}$ multilayer composite processed through hot pressing and rolling," Transactions of the Indian Institute of Metals, vol. 71, no. 9, pp. 2269-2274, 2018.

[29] G. L. Shen, G. K. Hu, and B. Liu, Mechanics of Composite Materials, Tsinghua University Press, Beijing, China, 2013, in Chinese.

[30] L. L. Liang, Finite Element Simulation of the Hot Roll Bonding Process of TC4-6061 Laminated Composite, Yanshan University, Qinhuangdao, China, 2015, in Chinese.

[31] J. Ji, Research on Roll Bonding Process of Titanium-7A52 Aluminum Alloy Clad Sheets, Northeastern University, Shenyang, China, 2012, in Chinese. 